\title{
The natural history of the Guillain-Barré syndrome in 18 children and 50 adults
}

\author{
R P KLEYWEG, F G A VAN DER MECHE, M C B LOONEN, J DE JONGE,* B KNIP \\ From the Department of Neurology, University Hospital Dijkzigt, Rotterdam and St Elisabeth Ziekenhuis,* \\ Tilburg, The Netherlands
}

SUMMARY Plasma exchange (PE) is indicated in adult patients with a severe Guillain-Barré syndrome (GBS). For children this has not been proven. If the disease runs a milder course in children, the problems experienced with PE might outweigh the benefit. In order to evaluate the need for such a specific treatment in children, we compared the severity of the disease between 18 children and 50 adults; no significant differences were found. The mean duration of hospitalisation of all children was 84 days, four children needed artificial ventilation for a mean of 21.5 days and two children died. We conclude therefore that PE is indicated in children with a severe GBS. The final decision, however, depends also on the practical feasibility of the procedure.

The Guillain Barré syndrome (GBS) is a monophasic polyneuropathy from which many patients ultimately recover satisfactorily. However, artificial respiration is necessary in $10-20 \%$ of the patients in the acute phase of the disease, $10-22 \%$ finally remain disabled and there is a mortality of $3-5 \% .^{1-3}$ For these reasons, an effective treatment has been sought and at present plasma exchange (PE) is generally accepted as such, early in the course of the GBS. ${ }^{4}$

In all trials leading to the acceptance of $\mathrm{PE}$, children were excluded. ${ }^{5-7}$ Although the effect of PE in children is not really known, there is no reason to assume that it would not be effective. Case studies have shown that treatment related improvement does occur in children ${ }^{8}$ (one of three cases has recently been published').

The practical problems of PE, however, especially in small children, make us reluctant to apply this treatment. Moreover, it has been suggested that the outcome of GBS in children might be more favourable, ${ }^{10}$ making such a specific treatment unnecessary.

To enable us to take the clinical decision about treatment with PE in children, it seems necessary to have more knowledge about the natural history of the GBS in children compared with adults. Systematic

Address for reprint requests: R P Kleyweg, MD, Department of Neurology, University Hospital Dijkzigt, 40 Dr Molewaterplein, 3015 GD Rotterdam, The Netherlands.

Received 29 November 1988 and in revised form 10 March 1989. Accepted 22 March 1989 studies on this subject are, however, not available. Several reports on the severity of the GBS in children are difficult to interpret because of variable methodology between and within the studies. ${ }^{10-13}$ They suggest, however, that the acute phase might be more severe and clinical outcome worse than generally thought, but patient selection prevents conclusions about children in general.

To evaluate the need for specific treatment in children we therefore studied retrospectively the clinical course of all children and adults admitted to our clinic from 1975 until the introduction of PE in 1985.

\section{Patients and methods}

Eighty four patients with a GBS according to the generally accepted criteria ${ }^{14}$ and admitted between 1975 and the time we started treating these patients with PE or immunoglobulin' (for adults 1985, for children 1987) were screened for inclusion in the study. Patients with predominant involvement of the cranial nerves (two children and four adults) or the sensory system (one adult) were excluded as well as patients with severe concurrent medical disorders interfering with functional abilities (three adults: one with severe asthma, one with disabling rheumatoid arthritis and one patient with multiple myeloma). Six patients (one child, five adults) lived too far away for follow-up in our hospital and were therefore excluded. From four adults we know, however, that they recovered between six months and three years after onset of the disease. The only child in this group had already considerably recovered at the time of discharge. We could not obtain any further information about one adult who could at least walk some distance unaided at the time he left hospital. 
Ultimately, 68 patients were studied: 18 children and 50 adults. None of these patients was treated with PE or immunoglobulin. The clinical characteristics that were used to delineate the clinical course were: duration of the disease until maximum disability, duration of artificial ventilation, duration of hospitalisation, and functional outcome one and two years after onset of the disease.

The functional status was assessed according to the grading system used in the North American trial, ${ }^{5}$ which we modified slightly (table 1).

A clear distinction between grades 0 and 1 could not be made in retrospect, and so these grades have been combined, implying good recovery.

In the final analysis, the patients were split into two groups: patients who had made a good recovery $(0 / 1)$ and patients who had a residual handicap or had died (grades $2-6$ ). The great majority of the information was available in the medical records: sometimes the general practitioner was consulted in order to complete the follow-up data.

\section{Results}

In the 18 children studied the age varied between 1 and 14 years (median 7) whereas in the 50 adults, the age range was 16 to 74 years (median 32 ).

\section{Severity of the disease (table 2)}

Time until nadir was similar in both groups. Four $(22 \%)$ children required artificial ventilation versus 15 $(30 \%)$ in the adult group (not significant, Fisher exact test). Median duration of artifical ventilation was 21.5 days in children and 32 days in adults (not significant, Mann Whitney U Test). Duration of hospitalisation (including rehabilitation centre) was equal in the two groups, 84 and 86 days respectively.

\section{Final outcome}

The functional outcome was assessed after one and two years (table 3 ) using the functional grading scale (table 1). As mentioned before, functional grades 0 and 1 have been combined, indicating good recovery. In both groups the majority of patients had already recovered completely or nearly completely after one year; there was a slight increase in the number of recovered patients after two years in both groups. Two children died from cardiac arrest, one in the acute phase, one early in the plateau phase. In both cases death had been preceded by severe fluctuations in

\section{Table 1 Functional grading system}

\footnotetext{
$0=$ healthy

$1=$ minor symptoms and signs, fully capable of manual work

$2=$ able to walk $>10 \mathrm{~m}$ without any assistance

$3=$ able to walk $>10 \mathrm{~m}$ with a walker or support

$4=$ bed or chair-bound (unable to walk $>10 \mathrm{~m}$ with a walker or support)

$5=$ assisted ventilation required for at least part of the day

$6=$ dead
}

Table 2 Severity of the disease

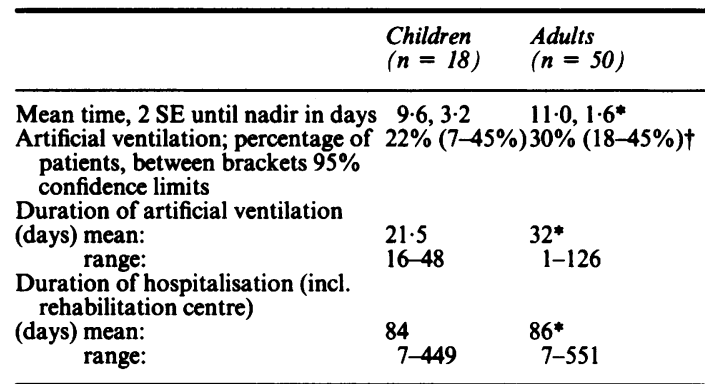

*not significant: Mann Whitney U-test.

tnot significant: Fisher exact test.

heart rate and blood pressure. One other child, a 10 year old boy, had not made a good recovery within two years; he was in functional group 2. In the adult group, four patients were found to have made an incomplete recovery after two years; one was confined to a wheelchair ( 38 years) and three were in functional group 2 (23, 39 and 46 years respectively). When patients in grade 2-6 are considered together, three $(17 \%)$ children had not recovered completely after 2 years (this included two deaths), versus four $(8 \%)$ adult patients (table 4).

\section{Discussion}

Using artificial ventilation, length of hospitalisatio and functional outcome after one and two years as parameters for the severity of the disease, we have not been able to demonstrate statistically significant differences between 18 children and 50 adults. The $95 \%$ confidence limits are, however, rather large reflecting the relatively small number of patients. Therefore no definite conclusions regarding the similarity of the two groups can be drawn; in fact, either group may be more severely affected. Recently it has been demonstrated that the prognosis is worse for adults over 40 years of age ${ }^{15}$ compared with younger adults. It might thus be reasonable to consider children and adults under 40 years of age as a single group having a better prognosis than the older patients.

It has recently been shown that the duration of the

Table 3 Outcome

\begin{tabular}{llllll}
\hline \multirow{2}{*}{$\begin{array}{l}\text { Functional } \\
\text { grade }\end{array}$} & \multicolumn{2}{l}{ One Year } & \multicolumn{3}{l}{ Two Years } \\
\cline { 2 - 3 } \cline { 5 - 6 } & Children & Adults & & Children & Adults \\
\hline $0 / 1$ & $14(77 \%)$ & $43(86 \%)$ & $15(83 \%)$ & $46(92 \%)$ \\
2 & $1(6 \%)$ & $4(8 \%)$ & $1(6 \%)$ & $3(6 \%)$ \\
3 & $1(6 \%)$ & $1(2 \%)$ & - & $-1(2 \%)$ \\
4 & - & $2(4 \%)$ & - & - \\
5 & $2(11 \%)$ & - & $2(11 \%)$ & - \\
6 & & & & &
\end{tabular}


Table 4 Outcome (continued)

\begin{tabular}{llllll}
\hline \multirow{2}{*}{$\begin{array}{l}\text { Functional } \\
\text { grade }\end{array}$} & \multicolumn{2}{l}{ One Year } & & \multicolumn{2}{l}{ Two Years } \\
\cline { 2 - 3 } \cline { 5 - 6 } & Children & Adults & & Children & Adults \\
\hline $0 / 1$ & $14(77 \%)$ & $43(86 \%)$ & $15(83 \%)$ & $46(92 \%)$ \\
$2 / 6$ & $4(23 \%)$ & $7(14 \%)$ & $3(17 \%)$ & $4(8 \%)$ \\
\hline
\end{tabular}

disease before the lowest point is reached is of prognostic importance. ${ }^{16}$ Again this parameter did not differ between the two groups. The percentage of patients who needed artificial ventilation is somewhat larger than generally mentioned in the literature, presumably because our hospital is also a secondary referral centre for more severely affected patients. In both groups the percentage of patients who finally made a complete recovery is in agreement with the literature. ${ }^{3}$

For a description of the severity of the GBS, we chose to focus not only on the final outcome but also on the duration of artificial ventilation, and the duration of hospitalisation. These latter parameters concerning disease severity are frequently not mentioned when discussing the need for treatment, and only the final outcome is taken into account. ${ }^{10}$ The duration of hospitalisation and artificial ventilation with its complications, are also important factors influencing the decision whether or not to apply PE, especially since these latter factors can be influenced by PE. ${ }^{\text {s }}$

From our data, we conclude that specific treatment should also be considered in children with GBS and not only in adults. Although the ultimate outcome is often excellent, it would certainly not seem superfluous to attempt to influence the clinical course: the mean duration of hospitalisation of all children has been 84 days and the mean duration of artificial ventilation in four children 21.5 days.

Although plasma exchange has proved its beneficial effects in clinical trials performed exclusively in adults, there is no reason to believe that it would be less effective in children. Case reports, including our own observations $^{89}$ suggest beneficial effects. Plasma exchange, however, is a cumbersome procedure with practical difficulties especially in smaller children. It should therefore be reserved for more severely affected children, in whom the beneficial effect of PE will outweigh the technical difficulties.

In the near future, high dose immunoglobulins might be an alternative, even for the smallest children. Recently, we described the promising experience with this treatment in eight GBS patients, including one 11 year old child. ${ }^{9}$ Application of this treatment must, however, await the results of the ongoing Dutch multicentre trial, (in which children are also included) to compare the effect of plasma exchange with immunoglobulin infusion.

We thank Dr P I M Schmitz for statistical advice and Ms $\mathbf{R} \mathbf{M}$ van den Hoven for secretarial help.

Preliminary results have been presented on the first conference of the European Neurological Society in June 1988. ${ }^{17}$

\section{References}

1 Pleasure DE, Lovelace RE, Duvoisin RC. The prognosis of acute polyradiculoneuritis. Neurology 1968;18: 1143-8.

2 McFarland HR, Heller GL, Arbor A. Guillain-Barré disease complex. A statement of diagnostic criteria and analysis of 100 cases. Arch Neurol 1966;14:196-201.

3 Löffel NB, Rossi LN, Mumenthaler M, Lütschg and Ludin HP. The Landry-Guillain-Barré Syndrome. Complications, prognosis and natural history in 123 cases. J Neurol Sci 1977;33:71-9.

4 Consensus Conference. The utility of therapeutic plasmapheresis for neurological disorders. JAMA 1986;256: 1333-7.

5 The Guillain-Barré Syndrome. Plasmapheresis and acute Guillain-Barré Syndrome. Neurology 1985; 35:1096-104.

6 Osterman PO, Lundemo G, Pirskanen R, Fagius J, Pihlstedt P, Siden A. Beneficial effects of plasma exchange in acute inflammatory polyradiculoneuropathy. Lancet 1984;ii:1296-9.

7 French Cooperative Group on Plasma Exchange in Guillain-Barré Syndrome. Efficiency of plasma exchange in Guillain-Barré Syndrome. Role of replacement fluids. Ann Neurol 1987;22:753-61.

8 Rotteveel JJ, Mullaart RA, Weemaes CMR, Empelen R van. Plasmaferese bij twee kinderen met het GuillainBarré Syndroom. T Kindergeneesk 1983;51:2:57-62.

9 Kleyweg RP, Meché FGA van der, Meulstee J. Treatment of Guillain-Barré Syndrome with high-dose gammaglobulin. Neurology 1988;38:1639-41.

10 Cole GF, Matthew DJ. Prognosis in severe GuillainBarré Syndrome. Arch Dis Child 1987;62:288-91.

11 Rossi LN, Mumenthaler M, Lütsch J, Ludin HP. Guillain-Barré Syndrome in children with special reference to the natural history of 38 personal cases. Neuropädiatrie 1976;7:42-51.

12 Briscoe DM, McMenamin JB, O'Donohoe NV. Prognosis in Guillain-Barré Syndrome. Arch Dis Child 1987;62:733-5.

13 Eberle E, Brink J, Azen S, White D. Early predictors if incomplete recovery in children with Guillain-Barré polyneuritis. J Pediatrics 1975;86:356-9.

14 Announcement: Criteria for diagnosis of Guillain-Barré Syndrome. Ann Neurol 1978;35:65-6.

15 Winer JB, Hughes RAC, Osmond C. A prospective study of acute idiopathic neuropathy. I. Clinical features and their prognostic value. J Neurol Neurosurg Psychiatry 1988;51:605-12. 
16 McKahn GM, Griffin JW, Cornblath DR, Mellits ED, Fisher RS, Quaskey SA. Plasmapheresis and GuillainBarré Syndrome: Analysis of prognostic factors and the effect of plasmapheresis. Ann Neurol 1988;23: 347-53.
17 Kleyweg RP, Meché FGA van der, Loonen MCB. Guillain-Barré syndrome; comparison of the natural course in children and adults. First meeting of the European Neurological Society, June 1988, Nice, France. J Neurol 1988;235:S14. 